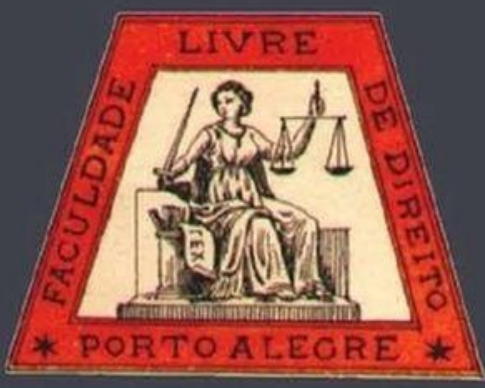

\title{
Das implicações do abandono afetivo nas relações familiares
}

On the implications of emotional abandonment in family relations

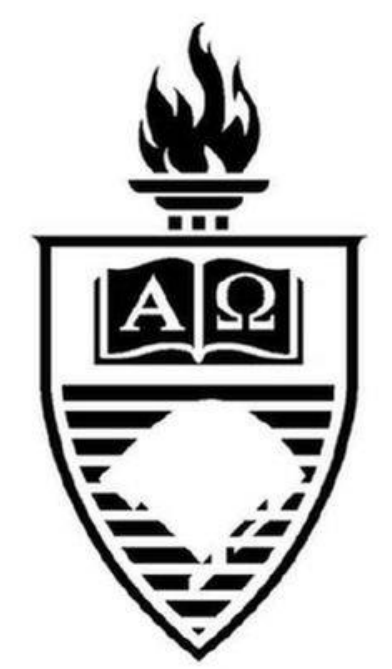

Valéria Silva Galdino Cardin

Centro Universitário de Maringá e

Universidade Estadual de Maringá

\section{Nádia Carolina Brencis Guimarães}

Universidade Estadual de Maringá

\section{Caio Eduardo Costa Cazelatto}

Centro Universitário de Maringá e

Universidade Estadual de Maringá

\section{UFRGS}




\title{
Das implicações do abandono afetivo nas relações familiares
}

\author{
On the implications of emotional abandonment in family relations
}

Valéria Silva Galdino Cardin ${ }^{*}$

Nádia Carolina Brencis Guimarães ${ }^{* *}$

Caio Eduardo Costa Cazelatto ${ }^{* * *}$

\section{REFERÊNCIA}

CARDIN, Valéria Silva Galdino; GUIMARÃES, Nádia Carolina Brencis; CAZELATTO, Caio Eduardo Costa. Das implicações do abandono afetivo nas relações familiares. Revista da Faculdade de Direito da UFRGS, Porto Alegre, n. 40, p. 224-242, ago. 2019.

\section{RESUMO}

Com a promulgação da atual Constituição Federal, as crianças e os adolescentes ganharam a proteção especial do Estado e são titulares de inúmeros direitos e garantias. O descumprimento dos direitos constitucionais dos infantes ocorre no seio familiar por meio do abuso do poder familiar. $\mathrm{O}$ afeto e a convivência familiar são elementos indispensáveis à formação da personalidade e da individualidade de uma pessoa. A relevância da participação de ambos os genitores no desenvolvimento de uma criança é significativa, já que as figuras paterna e materna representam papéis distintos na vida de um infante. Ressalta-se, que os filhos negligenciados são mais suscetíveis a desequilíbrios psicológicos. O descumprimento dos deveres parentais tem possibilitado ações de responsabilidade civil por ato ilícito causador de dano moral. A indenização seria o último recurso na tentativa de amenizar os danos psicológicos causados pelo abandono, já que na maioria das vezes não é mais possível restabelecer os laços de afeto. Por meio da evolução doutrinária, legislativa e jurisprudencial procurou-se demonstrar a pertinência do tema para a ampliação da responsabilidade advinda pelo não exercício da parentalidade responsável.

\section{ABSTRACT}

With the ratification of current Brazilian Constitution, children and adolescents acquired special protection from the state and are entitled to numerous rights. The violation of constitutional rights of infants occurs within the familial intimacy through the abuse of parental power. The affection and the family life are vital components to the formation of personality and individuality. The relevance of both parents' participation in the child's development is significant, since the paternal and maternal figures represent distinct roles in the infant's life. It is noteworthy that neglected children are more susceptible to psychological unbalances. The non-compliance of parental duties has enabled liability actions on the cause of pain and suffering. Compensation is a last resource in an attempt to minimize the psychological damage caused by abandonment, since most of the times it is no longer possible to restore the bonds of affection. Through the study of previous works, cases and the legislative evolution, the relevance of the theme is demonstrated in order to favor the increase in liability arising from the non-exercise of responsible parenting.

\footnotetext{
* Pós-doutora em Direito pela Universidade de Lisboa. Doutora e mestra em Direito das Relações Sociais pela Pontifícia Universidade Católica de São Paulo (PUC-SP). Docente da Universidade Estadual de Maringá (UEM) e do Programa de Pós-graduação em Ciências Jurídicas pelo Centro Universitário de Maringá (UNICESUMAR). Pesquisadora pelo Instituto Cesumar de Ciência, Tecnologia e Inovação (ICETI). Advogada no Paraná. E-mail: valeria@galdino.adv.br

** Acadêmica do curso de Direito da Universidade Estadual de Maringá (UEM) e Pesquisadora Discente pela referida Instituição. Membro do Núcleo de Estudos e Debates em Bioética e Biodireito (NEBIO/UEM). Membro do Núcleo de Estudos Constitucionais Prof. Zulmar Fachin (NEC/UEM). Membro do Núcleo de Estudos Penais (NEP-UEM). E-mail: nadia_cbg@yahoo.com.br

*** Mestre em Ciências Jurídicas pelo Centro Universitário de Maringá (Unicesumar). Bacharel em Direito pela Universidade Estadual de Maringá (UEM). Membro do Centro de Investigação Jurídico-Econômica (CIJE) da Faculdade de Direito da Universidade do Porto (FDUP). Advogado no Paraná.
} 
PALAVRAS-CHAVE

Direito de Família. Responsabilidade civil. Abandono afetivo.

\section{KEYWORDS}

Family law. Civil liability. Emotional abandonment.

\section{SUMÁRIO}

Introdução. 1. Da proteção jurídica da Criança e do Adolescente. 2. Do poder familiar e do abandono afetivo. 3. Da responsabilidade civil por danos morais. Conclusão. Referências.

\section{INTRODUÇÃO}

A atual Constituição Federal estabeleceu diversos direitos e garantias tendentes à proteção da família e de seus membros, especialmente aos que estão em situação de vulnerabilidade. O planejamento familiar é livre, contudo deve estar pautado no princípio da dignidade da pessoa humana e no exercício da parentalidade responsável, nos termos do artigo 226, $\S 7^{\circ}$, da Constituição Federal e, portanto, efetivar a convivência familiar às crianças e aos adolescentes, conforme dispõe o artigo 227 da Constituição Federal. Sendo assim, a relação paterno-filial ganhou novos contornos.

O exercício do poder familiar, enquanto múnus público, não contém apenas os direitos e deveres de ordem material dos pais em relação aos filhos, mas também deveres de ordem moral, como o cuidado, a assistência, a solidariedade e o respeito. Portanto, o exercício da parentalidade responsável requer que os pais prestem o mínimo de cuidado, o qual é fundamental para o desenvolvimento da personalidade de uma criança ou adolescente.

Acrescenta-se que o abandono afetivo surge do descaso parental, quando os genitores deixam de cumprir as atribuições oriundas da parentalidade. Muitos filhos são privados da oportunidade de conviver, receber afeto, cuidado, educação, bem como a devida assistência material e moral de seus pais, causando-lhes sérios prejuízos à personalidade.
Logo, a análise das consequências advindas do abandono afetivo faz-se necessário porque reflete de forma direta na formação da personalidade do filho, que no futuro, como cidadão, poderá acarretar problemas na sociedade do qual faz parte.

O estudo organiza-se em três partes. Inicialmente examina-se $\mathrm{o}$ processo de repersonalização das relações familiares e o reconhecimento do afeto enquanto valor jurídico e elemento constituinte dos laços familiares, bem como os inúmeros princípios constitucionais que incidem nas relações familiares, em especial no tocante ao relacionamento paterno-filial.

Posteriormente, realiza-se uma exposição acerca do poder familiar enquanto múnus público exercido no interesse do filho e do direito de visita como um direito-dever do pai e não mais como uma simples liberalidade do genitor não guardião. Esclarece-se o significado do abandono afetivo, bem como suas consequências. Ressalta-se, ainda, que o afeto neste trabalho é traduzido em cuidado.

Finalmente, examinam-se as ações decorrentes de abandono afetivo e os pressupostos necessários para o ensejo da responsabilidade por dano moral. Explica-se que a indenização não tem por intuito responsabilizar alguém pela ausência de amor, uma vez que não se pode cobrar o mesmo, tampouco atribuir valores pecuniários.

Para tanto, a pesquisa desenvolveu-se por meio do método teórico que consiste na consulta de obras, artigos de periódicos, 
documentos eletrônicos, bem como as decisões dos Tribunais pátrios que tratam do assunto.

\section{DA VALORIZAÇÃO DO AFETO E DA PROTEÇÃO JURÍDICA DA CRIANÇA E DO ADOLESCENTE}

A família inicialmente organizava-se segundo o modelo patriarcal, no qual mulheres, filhos e servos estavam subordinados ao poder absoluto do pater familia. $\mathrm{O}$ autoritarismo centrado na figura masculina impedia $o$ reconhecimento de direito aos outros componentes da família. $O$ afeto não era um elemento preponderante nessa organização familiar. A razão principal de sua união era a religião do fogo sagrado, a qual era mais forte e representativa que o nascimento, os sentimentos ou a força física. ${ }^{1}$

A utilização dos métodos contraceptivos e a entrada da mulher no mercado de trabalho exigiram a participação do homem nas obrigações domésticas, contribuindo para a organização nuclear da família, alterando assim a relação de subordinação familiar para uma relação de companheirismo e afetividade, o que transformou a relação entre os pais e os filhos. ${ }^{2}$

No ordenamento jurídico pátrio, até a promulgação da atual Constituição Federal, os filhos ocupavam um espaço desprivilegiado na estrutura jurídica. A família positivada era constituída pelo matrimônio e orientava-se pelo autoritarismo do pai, nas relações de cunho econômico e na continuidade da "tradição do nome" da família.

\footnotetext{
${ }^{1}$ COULANGES, Fustel de. A cidade antiga. 7. ed. Trad. José Cretella Júnior. São Paulo: R., 2011, p. 54-57.

${ }^{2}$ PEREIRA, Rodrigo da Cunha. Princípios fundamentais $e$ norteadores para a organização jurídica da família. 2005. 157 f. Tese (Doutorado em Direito) - Universidade Federal do Paraná, Curitiba, 2004. Disponível em: <http://dspace.c3sl.ufpr.br/dspace/bitstream/handle/1884 /2272/tese_dr. rodrigo da cunha.pdf?sequence $=1>$. Acesso em: 10 ago. 2018.
}

A família constitucionalizada apoia-se sobre o afeto, o cuidado e o desejo de estar junto. Compõe-se então o conceito de família eudemonista, que propicia à realização pessoal de cada membro, deixando a família de ser um fim em si mesma para ser um meio social para a busca da felicidade na relação com o outro. ${ }^{3}$

A Constituição Federal, no artigo $1^{\circ}$, inciso III, ao instituir a dignidade da pessoa humana como fundamento da República, deu início ao processo de repersonalização das relações jurídicas e especialmente familiares, deslocando a proteção jurídica do patrimônio para o próprio indivíduo a fim de proteger os direitos fundamentais e personalíssimos deste. ${ }^{4}$

A solidariedade é um dos objetivos fundamentais da República, nos termos do artigo $3^{\circ}$, inciso I, da Constituição Federal. Logo, a família, por ser a base da sociedade, conforme dispõe o artigo 226, caput da Constituição Federal, é o ambiente onde os indivíduos se preparam para a vida, sendo ainda o espaço ideal para o desenvolvimento das relações solidárias, já que a boa organização familiar repercute em uma sociedade mais democrática, igualitária e não-discriminatória.

A solidariedade familiar não concentra a titularidade de direitos apenas no grupo familiar enquanto coletividade, mas também na figura de cada um dos seus integrantes, estabelecendo assim deveres recíprocos entre os seus componentes. ${ }^{5}$ Portanto, nas relações familiares, deve-se promover a dignidade de

3 GAGLIANO, Pablo Stolze; PAMPLONA FILHO, Rodolfo. Novo Curso de Direito Civil: Direito de Família. 2. ed. São Paulo: Saraiva, 2012, v. 6. p. 101-102.

${ }^{4}$ LÔBO, Paulo. Direito civil: famílias. 4. ed. São Paulo: Saraiva, 2011. p. 23-29.

5 LÔBO, Paulo. O princípio constitucional da solidariedade nas relações de família. In: CONRADO, Marcelo; PINHEIRO, Rosalice Fidalgo (Coord.). Direito Privado e Constituição: ensaios para uma recomposição valorativa da pessoa e do patrimônio. Curitiba: Juruá, 2009. p. 330-338. 
cada um de seus membros e não apenas a do grupo familiar. ${ }^{6}$

O princípio da igualdade, previsto no caput do artigo $5^{\circ}$ da Constituição Federal, reconhece que todos são iguais perante a lei, sem distinção de qualquer natureza. A igualdade nas relações familiares se manifesta de dois modos: na reciprocidade de direitos e deveres entre os cônjuges, conforme dispõe o artigo $226, \S 5^{\circ}$, da Constituição Federal e o artigo 1.511 do Código Civil, e na proibição da discriminação dos filhos com base em sua origem, garantindo-lhes iguais direitos e qualificações, nos termos do artigo 227, § $6^{\circ}$, da Constituição Federal combinado com o artigo 1596 do Código Civil e o artigo 20 do Estatuto da Criança e do Adolescente.

Maria Berenice Dias leciona que "agora a palavra 'filho' não comporta mais nenhum adjetivo. Não mais cabe falar em filhos legítimos, ilegítimos, naturais, incestuosos, espúrios ou adotivos. Filho é simplesmente "filho", 7

Os direitos fundamentais positivados pelo constituinte no Título II da Constituição não excluem outros direitos decorrentes do regime e dos princípios por ela adotados ou dos tratados internacionais de que a República Federativa do Brasil seja parte, conforme o artigo $5^{\circ}, \S 2^{\circ}$, da Constituição Federal, assim todos os direitos ligados à dignidade da pessoa humana ou com a limitação do poder serão também direitos fundamentais, embora não estejam expressos no texto constitucional. ${ }^{8}$

O princípio da afetividade não está expresso na Constituição, mas foi reconhecido gradualmente como valor jurídico e direito da

\footnotetext{
${ }^{6}$ GAMA, Guilherme Calmon Nogueira da. Das relações de parentesco. In: DIAS, Maria Berenice; PEREIRA, Rodrigo da Cunha (Org.). Direito de Família e o Novo Código Civil. 3. ed. Belo Horizonte: Del Rey, 2003. p. 105.

${ }^{7}$ DIAS, Maria Berenice. Manual de direito das famílias. 6. ed. São Paulo: Revista dos Tribunais, 2010. p. 69.

8 MARMELSTEIN, George. Curso de Direitos Fundamentais. São Paulo. Atlas, 2008. p. 191.
}

personalidade resultante dos princípios da solidariedade e da dignidade da pessoa humana. ${ }^{9}$ Assim, Paulo Lôbo explica que a afetividade é empregada no texto constitucional no estabelecimento da igualdade entre os filhos (artigo 227, § $6^{\circ}$ ); na adoção como escolha afetiva (artigo 227, $\S \S 5^{\circ}$ e $6^{\circ}$ ); na proteção constitucional das estruturas familiares não advindas do matrimônio (artigo 226, § $4^{\circ}$ ); e na garantia da convivência familiar com prioridade absoluta à criança e ao adolescente (artigo 227). ${ }^{10}$

Percebe-se, então, que a afetividade é imposta como um dever a ser observado nas relações familiares, garantindo a construção de um espaço saudável ao desenvolvimento de cada um dos seus membros.

O cuidado é um subprincípio da dignidade da pessoa humana e um direito fundamental da criança e do adolescente, que também está implícito no texto constitucional.

Guilherme Calmon Nogueira da Gama explica:

[...] o cuidado como valor jurídico implícito do ordenamento jurídico brasileiro acentua e potencializa a dignidade da pessoa humana na dimensão da solidariedade, do compromisso e da responsabilidade de cada pessoa para com todas as outras, em especial no âmbito das relações familiares (incluindo a noção de parentalidade responsável). ${ }^{11}$

O cuidado como valor jurídico atende as “inúmeras situações de vulnerabilidade, sua identificação também está ligada à solidariedade,

${ }^{9}$ CARDIN, Valéria Silva Galdino; FROSI, Vitor Eduardo. $\mathrm{O}$ afeto como valor jurídico. In: ENCONTRO NACIONAL DO CONPEDI, 19., 9-12 jul. 2010, Fortaleza. Anais... Florianópolis: Fundação Boiteux, 2010. ${ }^{10}$ LÔBO, Paulo. Direito civil: famílias. 4. ed. São Paulo: Saraiva, 2011. p. 71.

11 GAMA, Guilherme Calmon Nogueira da. A parentalidade responsável e o cuidado: novas perspectivas. Revista do Advogado, São Paulo, v. 101, p. 29-36, dez. 2008. p. 32. 
à tolerância, à paciência e, especialmente, à prevenção". ${ }^{12}$ Toda vez que um indivíduo estiver em uma situação de vulnerabilidade em decorrência de negligência dos genitores com suas necessidades básicas, sejam materiais ou psíquicas, o Direito deve garantir-lhe proteção.

No artigo 227 da Constituição Federal, o cuidado é abordado em relação aos infantes ao estabelecer como atribuição da família colocar a criança e o adolescente a salvo de toda forma de negligência, discriminação, exploração, violência, crueldade e opressão.

A convivência familiar, enunciada no artigo 227 da Constituição Federal, é um direito fundamental expressamente assegurado a toda criança e adolescente. A convivência familiar fortalece laços afetivos e proporciona proteção à criança. ${ }^{13}$ Kátia Maciel, citando Tarcísio José Martins Costa, explica que a convivência familiar, "antes de ser um direito, é uma necessidade vital da criança, no mesmo patamar de importância do direito fundamental à vida". ${ }^{14}$

A convivência familiar, em razão de sua importância para o bom desenvolver dos infantes, é direito assegurado em todo o conjunto de normas relativas às crianças e aos adolescentes.

A Constituição de 1988 e o Estatuto da Criança e do Adolescente tiraram os menores da condição de objeto do direito e os consagraram como sujeitos de direitos. Foi atribuído à família, à sociedade e ao Estado o dever de assegurar com absoluta prioridade a criança e aos adolescentes inúmeros direitos como a

\footnotetext{
12 PEREIRA, Tânia da Silva. Cuidado no Direito de Família, Infância e Juventude. Disponível em: <http://www.cartaforense.com.br/conteudo/entrevistas/cui dado-no-direito-de-familia-infancia-e-juventude/10588>. Acesso em: 6 ago. 2018.

${ }^{13}$ LÔBO, Paulo. Direito civil: famílias. 4. ed. São Paulo: Saraiva, 2011. p. 74.

${ }^{14}$ MACIEL, Kátia Regina Ferreira Lobo Andrade. Direito Fundamental à Convivência Familiar. In: MACIEL, Kátia (Coord.). Curso de Direito da Criança e do Adolescente: aspectos teóricos e práticos. Rio de Janeiro: Lumen Juris, 2010. p. 75.
}

dignidade, respeito, liberdade, convivência familiar e comunitária, nos termos do artigo 227 da Constituição Federal.

Já o princípio do melhor interesse da criança e do adolescente está implicitamente disposto no artigo 227 da Constituição Federal ${ }^{15}$ combinado com os artigos $4^{\mathrm{ol}}$ e $6^{\mathrm{o}^{17}}$ do Estatuto da Criança e do Adolescente. O melhor interesse da criança e do adolescente, devido à sua condição peculiar de pessoa em desenvolvimento, busca a "efetividade dos direitos infanto-juvenis, os quais devem prevalecer sobre os interesses de outros indivíduos e instituições". ${ }^{18}$ Por intermédio dele

15 “Art. 227. É dever da família, da sociedade e do Estado assegurar à criança, ao adolescente e ao jovem, com absoluta prioridade, $\mathrm{o}$ direito à vida, à saúde, à alimentação, à educação, ao lazer, à profissionalização, à cultura, à dignidade, ao respeito, à liberdade e à convivência familiar e comunitária, além de colocá-los a salvo de toda forma de negligência, discriminação, exploração, violência, crueldade e opressão.

$\S 1^{\circ} \mathrm{O}$ Estado promoverá programas de assistência integral à saúde da criança, do adolescente e do jovem, admitida a participação de entidades não governamentais, mediante políticas específicas e obedecendo aos seguintes preceitos: $[\ldots]$."

16 "Art. $4^{\text {o }}$ É dever da família, da comunidade, da sociedade em geral e do poder público assegurar, com absoluta prioridade, a efetivação dos direitos referentes à vida, à saúde, à alimentação, à educação, ao esporte, ao lazer, à profissionalização, à cultura, à dignidade, ao respeito, à liberdade e à convivência familiar e comunitária.

Parágrafo único. A garantia de prioridade compreende:

a) primazia de receber proteção e socorro em quaisquer circunstâncias;

b) precedência de atendimento nos serviços públicos ou de relevância pública;

c) preferência na formulação e na execução das políticas sociais públicas;

d) destinação privilegiada de recursos públicos nas áreas relacionadas com a proteção à infância e à juventude."

17 “Art. $6^{\circ} \mathrm{Na}$ interpretação desta Lei levar-se-ão em conta os fins sociais a que ela se dirige, as exigências do bem comum, os direitos e deveres individuais e coletivos, e a condição peculiar da criança e do adolescente como pessoas em desenvolvimento."

${ }^{18}$ MICELI, Mariana Sant'Ana. Por uma visão crítica do Direito da Criança e do Adolescente. Revista Estudos Jurídicos UNESP, Franca, ano 14, n. 2, p. 275-288, 2010. Disponível 
procura-se "permitir o desenvolvimento físico, mental, espiritual e social, em condições de liberdade e dignidade [...]". ${ }^{19}$

A garantia do melhor interesse da criança relaciona-se ao princípio da parentalidade responsável, que é um desdobramento do planejamento familiar de livre decisão do casal, conforme estabelece o artigo 226, §7º da Constituição Federal, in verbis:

Art. 226. A família, base da sociedade, tem especial proteção do Estado. $\S 7^{\circ}$ Fundado nos princípios da dignidade da pessoa humana e da paternidade responsável, o planejamento familiar é livre decisão do casal, competindo ao Estado propiciar recursos educacionais e científicos para o exercício desse direito, vedada qualquer forma coercitiva por parte de instituições oficiais ou privadas.

A parentalidade responsável designa a responsabilidade natural dos pais sobre os filhos, que se inicia com a concepção e se estende enquanto for necessária. ${ }^{20}$ Os pais devem, então, primar pela garantia de um ambiente saudável e seguro para o crescimento dos filhos, proporcionando-lhes o mínimo necessário para o desenvolvimento integral de sua personalidade. ${ }^{21}$

A parentalidade responsável não incide somente sobre os filhos desejados e planejados, mas também na prole advinda do risco natural do exercício da sexualidade. A dignidade dos pais exercerem o planejamento familiar não pode se sobrepor a dignidade do filho que irá nascer. ${ }^{22}$ Aqueles que não querem assumir a responsabilidade de prover o mínimo de

\footnotetext{
<http://periodicos.franca.unesp.br/index.php/estudosjuridic osunesp/article/view/255 >. Acesso em: 12 ago. 2018.

19 GAMA, Guilherme Calmon Nogueira da. A parentalidade responsável e o cuidado: novas perspectivas. Revista do Advogado, São Paulo, v. 101, p. 29-36, dez. 2008. p. 32.

${ }^{20}$ BOSCHI, Fabio Bauab. Direito de visita. São Paulo: Saraiva, 2005. p.52.

${ }^{21}$ GAMA, op. cit., p. 32.

${ }^{22}$ Ibid., p. 31-35.
}

assistência afetiva, moral, intelectual e material não devem ter descendentes. ${ }^{23}$

\section{DO PODER FAMILIAR E DO ABANDONO AFETIVO}

O poder familiar na nova ordem constitucional deixa de ser um direito do pai sobre o filho e seu patrimônio e emerge como um poder-dever para os pais, que devem cuidar de seus filhos e de seu futuro. O poder familiar é um múnus público imposto pelo Estado aos pais e tem se desvinculado da ideia de um direito sobre os filhos para tornar-se um dever exercido no interesse dos filhos com "caráter eminentemente protetivo". ${ }^{24} \mathrm{O}$ poder familiar tem início com o reconhecimento da filiação independentemente de sua natureza: biológica ou socioafetiva.

Embora o Código Civil, no artigo 1.631, afirme que o poder familiar é exercido em conjunto pelos pais durante o casamento e a união estável, a doutrina entende isso como um equívoco e afirma que, enquanto houver o poder familiar, pai e mãe o exercem em conjunto independentemente do vínculo existente entre eles. ${ }^{25}$ Tendo em vista que o rompimento ou a inexistência da convivência conjugal do casal parental não altera os direitos e deveres dos pais para com os filhos, nos termos do artigo 1.579 do Código Civil, o exercício do poder familiar em igualdade de condições pelo pai e pela mãe atende a igualdade constitucional de direitos e

${ }^{23}$ CARDIN, Valéria Silva Galdino. Dano Moral no Direito de Família. São Paulo: Saraiva, 2012. p. 239.

24 GONÇALVES, Carlos Roberto. Direito civil brasileiro: Direito de Família. 9. ed. São Paulo: Saraiva, 2012. v. 6. p. 413.

${ }^{25}$ COELHO, Fábio Ulhoa. Curso de direito civil: Família Sucessões. 5. ed. São Paulo: Saraiva, 2012, v. 5. p. 204; GONÇALVES, op. cit., p. 415-416; LÔBO, Paulo. Do poder familiar. In: DIAS, Maria Berenice; PEREIRA, Rodrigo da Cunha (Org.). Direito de Família e o Novo Código Civil. 3. ed. Belo Horizonte: Del Rey, 2003. p. 184. 
obrigações entre homens e mulheres, previsto no artigo $5^{\circ}$, inciso I, do Código Civil.

De acordo com o artigo 1.634 do Código Civil, são atribuições dos pais, no exercício do poder familiar, o dever de dirigir a criação e a educação dos filhos e tê-los em companhia e guarda.

O dever de dirigir a criação e a educação dos filhos corresponde ao dever de assistir, criar e educar os filhos menores previsto no artigo 229 da Constituição Federal e ao dever de sustento, guarda e educação, estabelecido no artigo 22 do Estatuto da Criança e do Adolescente. Sendo assim, os pais em igualdade de condições devem zelar para que o desenvolvimento moral, material e intelectual do filho se dê em um ambiente saudável.

Proporcionar apenas recursos materiais e o acesso à escola não é suficiente para caracterizar o dever de sustento e educação do filho. O exercício da paternidade responsável exige a participação de ambos os genitores em todas as dimensões da vida do infante.

Paulo Lôbo explica:

A noção de educação, para fins da responsabilidade da família, é mais larga possível. Inclui a educação escolar, a formação moral, politica, profissional, cívica, que se dá em família e em todos os ambientes que contribuam para a formação do filho, como pessoa em desenvolvimento. ${ }^{26}$

Como regra, o Código Civil, no artigo 1.635, estabelece que o poder familiar é extinto pela morte dos pais ou do filho; pela emancipação; pela maioridade; pela adoção; ou por decisão judicial. Mas os pais podem ser suspensos do exercício do poder familiar quando faltarem aos deveres a eles estabelecidos, nos

26 LÔBO, Paulo. Famílias Contemporâneas e as Dimensões da Responsabilidade. In: PEREIRA, Rodrigo da Cunha (Coord.). Família e responsabilidade: teoria e prática do Direito de Família. Porto Alegre: Magister/IBDFAM, 2010. p. 25. termos do artigo 1.637, e caso haja reiteração nessas faltas os pais serão destituídos do poder familiar:

Art. 1.638. Perderá por ato judicial o poder familiar o pai ou a mãe que:

I - castigar imoderadamente o filho;

II - deixar o filho em abandono;

III - praticar atos contrários à moral e aos bons costumes;

IV - incidir, reiteradamente, nas faltas previstas no artigo antecedente.

V - entregar de forma irregular o filho a terceiros para fins de adoção.

Tanto o abandono material como o moral são causas para a suspensão e/ou destituição do poder familiar. Silvio Rodrigues explica que o abandono moral do filho se caracteriza como "descaso intencional pela sua criação, educação e moralidade". ${ }^{27}$

A perda do poder familiar decorrente do descumprimento dos deveres legais de criar e educar os filhos não isenta os pais das sanções penais para os crimes de abandono moral e intelectual previstas nos artigos 244 e 246 do Código Penal, e ainda assim estes poderão ser responsabilizados no âmbito civil pelo dano moral causado aos direitos da personalidade dos filhos. $^{28}$

O rompimento da sociedade conjugal, mesmo nos casos de estabelecimento da guarda unilateral, não deve interferir no relacionamento paterno-filial, conforme estabelecido pelo artigo 1.632 do Código Civil.

Nos casos em que seja fixada a guarda unilateral, o genitor não guardião é titular do direito de visita, nos termos do artigo 1.589 do Código Civil, e por meio dele deve cumprir as obrigações do poder familiar, e assim manter-se-

${ }^{27}$ RODRIGUES, Silvio. Direito civil. 26. ed. São Paulo: Saraiva, 2001. p. 363.

28 DINIZ, Maria Helena. Curso de Direito Civil Brasileiro: Direito de Família. 27. ed. São Paulo: Saraiva, 2012, v. 5. p. 607. 
ão a convivência e os laços de afeto entre o genitor e o filho, evitando que esses se dissolvam junto com o rompimento do casal parental.

Fabio Bauab Boschi explica a relevância do instituto do direito de visita para o desenvolvimento saudável do filho:

Assim, é no exercício obrigatório do dever de visita que o pai vai dar assistência a seu filho. Deve prestar-lhe não só assistência material, na forma de alimentos, mas também imaterial, consubstanciada no afeto, no carinho, aconchego, apoio moral, sustentação nas dificuldades da vida, aconselhamento, troca de experiências e defesa de seus direitos e interesses. $^{29}$

$\mathrm{O}$ direito de visita tem sido interpretado erroneamente. Durante um longo período se entendeu que era um direito de o pai visitar o filho e que estava a arbítrio de sua subjetividade e interesses. Hodiernamente, entende-se que o direito de visita é um dever do pai e direito do filho. ${ }^{30}$ Esse novo entendimento constitui um direito de visita que atende ao melhor interesse do filho e que se sobrepõe aos interesses dos pais. Maria Berenice Dias explica que não há mais o direito de visitar o filho, mas sim o dever de conviver com ele. ${ }^{31}$

A retirada do estado de filiação do domínio exclusivamente biológico e patrimonial anteriormente concebido e o reconhecimento do direito do filho à convivência familiar com

\footnotetext{
${ }^{29}$ BOSCHI, Fabio Bauab. Direito de visita. São Paulo: Saraiva, 2005. p. 54-55.

${ }^{30}$ LÔBO, Paulo. Direito civil: famílias. 4. ed. São Paulo: Saraiva, 2011. p. 74; DIAS, Maria Berenice. Manual de direito das famílias. 6. ed. São Paulo: Revista dos Tribunais, 2010. p. 440; MADALENO, Rolf. Curso de Direito de Família. 4. ed. Porto Alegre: Forense, 2011. p. 375; BOSCHI, op. cit., p. 51; LIRA, Wlademir Paes de. Direito da Criança e do Adolescente à Convivência Familiar e uma Perspectiva de Efetividade no Direito Brasileiro. In: PEREIRA, Rodrigo da Cunha (Coord.). Família e responsabilidade: teoria e prática do Direito de Família. Porto Alegre: Magister/IBDFAM, 2010. p. 528.

${ }^{31}$ DIAS, op. cit., p. 452.
}

ambos os genitores destacou a relevância da figura do abandono afetivo, consequência da não concretização dos direitos dos infantes e do exercício do poder familiar de forma não responsável que causa danos permanentes à personalidade dos filhos.

Paulo Lôbo assim o descreve:

[...] o "abandono afetivo" nada mais é que inadimplemento dos deveres jurídicos de paternidade. Seu campo não é exclusivamente o da moral, pois o direito o atraiu para si, conferindo-lhe consequências jurídicas que não podem ser desconsideradas. ${ }^{32}$

O abandono afetivo manifesta-se não pela ausência do afeto paterno enquanto sentimento voluntário, mas sim na ausência da afetividade enquanto dever jurídico imposto reciprocamente entre pais e filhos. ${ }^{33}$ Sob a perspectiva da dignidade humana e da solidariedade, os pais devem respeitar o direito do filho de conviver com ambos os genitores e ser cuidado por eles.

A função parental não consiste apenas no sustento material do filho, mas também em suprir suas necessidades morais e espirituais. Neste sentido Hans Jonas explica que: "O objetivo da responsabilidade parental é a criança como um todo e todas as suas possibilidades, e não apenas as suas carências imediatas". ${ }^{34}$

O cuidado é um elemento essencial à existência e ao crescimento de todos os seres humanos. Sendo assim, é inaceitável a ausência de apoio afetivo aos descendentes. ${ }^{35}$

A Ministra Nancy Andrighi, em julgado sobre o abandono afetivo, explica que o cuidado

\footnotetext{
${ }^{32}$ LÔBO, op. cit., p. 313.

${ }^{33}$ Ibid., p. 72.

34 JONAS, Hans apud LÔBO, Paulo. Famílias Contemporâneas e as Dimensões da Responsabilidade. In: PEREIRA (Coord.), op. cit., p.14.

35 GAMA, Guilherme Calmon Nogueira da. A parentalidade responsável e o cuidado: novas perspectivas. Revista do Advogado, São Paulo, v. 101, p. 29-36, dez. 2008. p. 31.
} 
para com o filho é uma obrigação jurídica que independe da vontade dos pais:

Aqui não se fala ou se discute o amar e, sim, a imposição biológica e legal de cuidar, que é dever jurídico, corolário da liberdade das pessoas de gerarem ou adotarem filhos. [...] Em suma, amar é faculdade, cuidar é dever. [...] com a decisão de procriar ou adotar, nasce igualmente o indelegável ônus constitucional de cuidar. ${ }^{36}$

A respeito do cuidado parental na formação moral e espiritual do infante, Giselda Hironaka ensina que o filho tem "direito ao pai" e o define como:

[...] direito atribuível a alguém de conhecer, conviver, amar e ser amado, de ser cuidado, alimentado e instruído, de se colocar em situação de aprender e apreender os valores fundamentais da personalidade e da vida humanas, de ser posto a caminhar e a falar, de ser ensinado a viver, a conviver e a sobreviver, como de resto é o que ocorre - em quase toda a extensão mencionada - com a grande maioria dos animais que compõem a escala biológica que habita e vivifica a face da Terra. ${ }^{37}$

$\mathrm{O}$ direito ao pai é também um direito à mãe. A participação do casal parental na vida do filho é importantíssima, e a ausência do referencial paterno ou materno prejudica $\mathrm{o}$

\footnotetext{
${ }^{36}$ BRASIL. Superior Tribunal de Justiça. Recurso Especial n. 1.159.242 - SP (2009/0193701-9). Recorrente: Antônio Carlos Jamas dos Santos. Recorrido: Luciane Nunes de Oliveira Souza. Relatora: Min. Nancy Andrighi. Brasília, 24 de abril de 2012. Revista Eletrônica da Jurisprudência do STJ, 10 maio 2012. p. 12. Disponível em: <https://ww2.stj.jus.br/websecstj/cgi/revista/REJ.cgi/ITA? seq $=1067604 \&$ tipo $=0 \&$ nreg $=200901937019 \&$ SeqCgrmaS essao $=\&$ CodOrgaoJgdr $=\& d t=20120510 \&$ formato $=P D F \& s$ alvar $=$ false $>$.

${ }^{37}$ HIRONAKA, Giselda. Direito ao pai. Revista Igualdade, v. 8 , n. 26, p. 34-36, 2000. Disponível em: <http://www2.mp.pr.gov.br/cpca/telas/ca_igualdade_22_2 2.php> Acesso em: 18 ago. 2018.
}

desenvolvimento das habilidades psíquicas e da personalidade do infante. ${ }^{38}$

Giselda Hironaka, em brilhante explanação, destaca a diferença entre a função materna e paterna na formação do filho:

Tanto o pai quanto a mãe concorre para que se organize convenientemente o desenvolvimento estrutural, psíquico, moral e ético do filho, cabendo à mãe um papel que mais se relaciona com a flexibilidade, com o afeto e com o conforto, enquanto ao pai cabe um papel que mais se relaciona com a fixação do caráter e da personalidade. A conjugação de ambos os papéis e a co-relação de seus efeitos são capazes de revelar, na maioria das vezes, uma pessoa mais harmoniosa sob muitos pontos de vista sociais e de acordo com muitos modelos culturais. ${ }^{39}$

Cita-se, ainda, que o abandono afetivo pode ocorrer nos casos em que um dos genitores é omisso publicamente quanto à existência do filho, causando diversas situações de constrangimento ao filho. $\mathrm{O}$ filho não é tratado com igualdade em relação aos irmãos e torna-se um filho de segunda categoria. ${ }^{40}$

Rolf Madaleno explica que muitas vezes os pais acabam por escolher alguns filhos em detrimento de outros como merecedores de afeto e que essa escolha se dá na maioria das vezes tendo em vista o relacionamento e os sentimentos que existe entre o casal parental. ${ }^{41}$

Reconhece-se que muitas vezes diversos empecilhos dificultam o exercício dos deveres parentais: dificuldades financeiras, compromissos profissionais ou familiares, distâncias geográficas. Mas isso não justifica que

\footnotetext{
${ }^{38}$ LÔBO, Paulo. Direito civil: famílias. 4. ed. São Paulo: Saraiva, 2011. p. 202.

39 HIRONAKA, Giselda. Os contornos jurídicos da responsabilidade afetiva na relação entre pais e filhos além da obrigação legal de caráter material. Disponível em: <www.flaviotartuce.adv.br/artigosc/Giselda_resp2. doc>. Acesso: 15 ago. 2018.

${ }^{40}$ BRASIL, op. cit., p. 13-14.

${ }^{41}$ MADALENO, Rolf. Curso de Direito de Família. 4. ed. Porto Alegre: Forense, 2011. p. 376.
} 
na era da globalização o pai se negue a cuidar de seu filho ou se informar sobre assuntos referentes ao seu sadio desenvolvimento. ${ }^{42}$

\section{DA RESPONSABILIDADE CIVIL POR DANOS MORAIS}

Ao permitir diferentes designações aos filhos tendo como base a sua origem, o Código Civil de $1916^{43}$ legitimava a irresponsabilidade dos pais em relação à prole havida fora do casamento. Em decorrência da impossibilidade de reconhecê-los, não havia direitos ou deveres decorrentes da responsabilidade natural da relação paterno-filial. Paulo Lôbo esclarece que "[...] livre era o genitor do filho ilegítimo e, consequentemente, irresponsável". ${ }^{44}$

A Constituição de 1988 rompeu com o paradigma da irresponsabilidade parental ao estabelecer os mesmos direitos e qualificações aos filhos independentemente de sua origem, conforme previsto no artigo $227, \S 6^{\circ}$. Abriu-se, então, o caminho para a responsabilização dos pais por quaisquer atos que violem os direitos dos filhos.

Por consequência, nas últimas décadas, os genitores começaram a ser demandados juridicamente para reparação dos danos causados pelo abandono afetivo dos filhos. Analisa-se a partir de então os aspectos relativos à responsabilização civil por dano moral decorrente do abandono afetivo.

Por meio da responsabilidade civil procura-se fazer com que os prejuízos patrimoniais ou extrapatrimoniais causados por

\footnotetext{
${ }^{42}$ MADALENO, Rolf. Curso de Direito de Família. 4. ed. Porto Alegre: Forense, 2011. p. 379.

43 “Art. 332. O parentesco é legitimo, ou ilegítimo, segundo procede, ou não de casamento; natural, ou civil, conforme resultar de consanguinidade, ou adoção."

44 LÔBO, Paulo. Famílias Contemporâneas e as Dimensões da Responsabilidade. In: PEREIRA, Rodrigo da Cunha (Coord.). Família e responsabilidade: teoria e prática do Direito de Família. Porto Alegre: Magister/IBDFAM, 2010. p. 20.
}

um terceiro sejam reparados. O responsabilizado pode ser o autor da conduta danosa, um objeto ou alguém que seja sob sua responsabilidade, podendo advir ainda de mera imposição legal. ${ }^{45}$

A reparação civil visa devolver ao lesado quando possível o status quo ante. ${ }^{46}$

O fundamento jurídico da responsabilização civil está no artigo 927 do Código Civil, que estipula a obrigação do sujeito reparar os danos causados por ato ilícito, podendo este advir de uma ação ou omissão voluntária (artigo 186) ou de um abuso de direito (artigo 187).

O dano corresponde a prejuízos causados aos bens juridicamente tutelados. O dano moral causa lesões em bens inexpressíveis financeiramente como os direitos fundamentais e personalíssimos. $^{47}$

Yussef Said Cahali leciona acerca do dano moral:

Na realidade, multifacetário o ser anímico, tudo aquilo que molesta gravemente a alma humana, ferindo-lhe gravemente os valores fundamentais inerentes à sua personalidade ou reconhecidos pela sociedade em que está integrado, qualifica-se, em linha de princípio, como dano moral; não há como enumerá-los exaustivamente, evidenciando-se na dor, na angústia, no sofrimento, na tristeza pela ausência de um ente querido falecido; no desprestígio, na desconsideração social, no descrédito à reputação, na humilhação pública, no devassamento da privacidade; no desequilíbrio da normalidade psíquica, nos traumatismos emocionais, na depressão ou no

45 DINIZ, Maria Helena. Curso de Direito Civil Brasileiro: Responsabilidade Civil. 26. ed. São Paulo: Saraiva, 2012. v. 7. p. 51.

46 CAVALIERI FILHO, Sergio. Programa de responsabilidade civil. 8. ed. São Paulo: Atlas, 2009. p. 13. 47 CARDIN, Valéria Silva Galdino. Dano Moral no Direito de Família. São Paulo: Saraiva, 2012. p. 234-241. 
desgaste psicológico, nas situações de constrangimento moral. ${ }^{48}$

Portanto, o abandono afetivo parental se manifesta como ato ilícito, previsto no artigo 186, causador de dano moral por ser uma conduta omissiva e negligente do genitor que deixa de cumprir os deveres inerentes à paternidade, causando enorme sofrimento ao filho negligenciado.

A reponsabilidade nas relações familiares é subjetiva ${ }^{49}$. Sendo assim, em todas as ações decorrentes de abandono afetivo é necessária a existência de culpa.

A culpa, para fins do Código Civil, não é apenas a lato sensu correspondente à intenção de atingir o efeito da conduta, ou seja, produzir o dano, mas abrange também a culpa stricto sensu na qual a ação não tem por objetivo especifico a produção, mas o dano, por ser previsível, poderia ser evitado por meio da adoção de conduta diversa. ${ }^{50}$

Sergio Cavalieri Filho conceitua a culpa como "conduta voluntária contrária ao dever de cuidado imposto pelo Direito, com a produção de um evento danoso involuntário, porém previsto e previsível". 51

A ausência de previsão explicita do dever de prestar afeto não pode ser arguida como excludente de ilicitude, já que o ato ilícito se configura também como a violação de um direito e não exclusivamente de uma lei. ${ }^{52} \mathrm{O}$ ordenamento jurídico brasileiro não é taxativo em relação aos casos passiveis de reparação

\footnotetext{
${ }^{48}$ CAHALI, Yussef Said. Dano moral. São Paulo: RT, 2005. p. 22.

${ }^{49}$ MADALENO, Rolf. O dano moral na investigação de paternidade. Disponível em: <http://www.rolfmadaleno.com.br/novosite/conteudo.php? id=32\#_ftnref11>. Acesso em: 19 ago. 2018.

50 GONÇALVES, Carlos Roberto. Direito civil brasileiro: Responsabilidade Civil. 7. ed. São Paulo: Saraiva, 2012. v. 4. p. 272.

51 CAVALIERI FILHO, Sergio. Programa de responsabilidade civil. 8. ed. São Paulo: Atlas, 2009. p. 34. 52 GONÇALVES, op. cit., p. 83.
}

civil. Há o estabelecimento legal de cláusulas gerais, mas compete ao Poder Judiciário analisar quais danos devem ser indenizáveis. ${ }^{53}$

O dano moral decorrente do abandono afetivo procede da violação à lei e aos direitos dos filhos, caracterizando o dano in re ipsa. ${ }^{54}$

A existência do nexo de causalidade (relação direta) entre o dano e a conduta do agente é essencial para a incidência da responsabilidade civil e para a admissibilidade do pedido de reparação. ${ }^{55}$ No caso do abandono afetivo, dar-se-á com a demonstração de que o genitor faltou com deveres legais inerentes ao exercício da parentalidade responsável.

Rolf Madaleno considera o abandono afetivo como abuso de direito, nos termos do artigo 187 do Código Civil, o qual se configura pelo exercício de um direito subjetivo que extrapola os limites impostos pelo seu fim econômico ou social, pela boa-fé ou pelos bons costumes. Ao desrespeitar as barreiras do direito do filho, o genitor deverá responder pelos danos causados pelo excesso, ainda que sejam apenas morais.

O autor explica:

$\mathrm{O}$ abuso do direito independe da culpa, pois sua noção extrapola a teoria da responsabilidade civil. Trata da imposição de restrições éticas ao exercício de direitos subjetivos, tendo em conta que no âmbito do conteúdo do direito de visitas e na obrigação

53 SCHREIBER, Anderson. Novos paradigmas da responsabilidade civil. 2. ed. São Paulo: Atlas, 2009. p. 100.

${ }^{54}$ BRASIL. Superior Tribunal de Justiça. Recurso Especial n. 1.159.242 - SP (2009/0193701-9). Recorrente: Antônio Carlos Jamas dos Santos. Recorrido: Luciane Nunes de Oliveira Souza. Relatora: Min. Nancy Andrighi. Brasília, 24 de abril de 2012. Revista Eletrônica da Jurisprudência do STJ, 10 maio 2012. passim. Disponível em: <https://ww2.stj.jus.br/websecstj/cgi/revista/REJ.cgi/ITA? seq $=1067604 \&$ tipo $=0 \&$ nreg $=200901937019 \&$ SeqCgrmaS essao $=\&$ CodOrgaoJgdr $=\& \mathrm{dt}=20120510 \&$ formato $=$ PDF $\& s$ alvar=false $>$.

55 DINIZ, Maria Helena. Curso de Direito Civil Brasileiro: Responsabilidade Civil. 26. ed. São Paulo: Saraiva, 2012. v. 7. p. 129. 
de comunicação com seus filhos, existem espaços que não podem ser relegados e barreiras que não podem ser ultrapassadas. ${ }^{56}$

O pai, ao deixar o filho em abandono, abusa do poder familiar e do direito de visita ausentando-se de cumprir com os deveres naturais da paternidade, deixando de cuidar, orientar e conviver com o filho.

Há uma intensa resistência dos Tribunais na aplicação da responsabilidade civil nas relações de família por considerar que o direito de família possui princípios próprios e que não se devem aplicar institutos das relações obrigacionais. ${ }^{57}$ Porém, uma vez que a responsabilidade civil aplica-se entre estranhos com maior razão, deve incidir em relação aos entes familiares que gozam da intimidade um do outro, entre os quais deve prevalecer o respeito mútuo e a solidariedade.

Embora o ordenamento jurídico já adote a perda do poder familiar como uma medida de "punição" para os genitores que não cumpram com seus deveres morais e/ou materiais, conforme disposição do artigo 1.637 combinado com o artigo 1.638, ambos do Código Civil, é necessária a adoção de uma postura mais rígida, tendo em vista que para o genitor que já deixou o filho em abandono, a perda do poder familiar não seria exatamente uma sanção, mas sim uma premiação, a qual o libertaria definitivamente dos encargos que não deseja cumprir. ${ }^{58}$

A principal função da destituição do poder familiar nos casos de abandono não tem por objetivo compensar os prejuízos causados

\footnotetext{
56 MADALENO, Rolf. O custo do abandono afetivo. Disponível em: <http://www.rolfmadaleno. com.br/novosite/conteudo.php?id=943> Acesso em: 16 ago. 2018.

${ }^{57}$ BRASIL. Superior Tribunal de Justiça. Recurso Especial n. 757.411 - MG (2005/0085464-3). Recorrente: V.P.F.O. Recorrido: A. B. F. (menor), assist. por V. B. F. Relator: Min. Fernando Gonçalves. Brasília, 29 nov. 2005. DJU, 27 mar. 2006.

58 DIAS, Maria Berenice. Manual de direito das famílias. 6. ed. São Paulo: Revista dos Tribunais, 2010. p. 435.
}

aos filhos, mas sim proporcionar ao menor melhores condições para que lhe seja fornecido o necessário ao seu pleno desenvolvimento. ${ }^{59}$

Reitera-se que proporcionar apenas recursos materiais não é o suficiente para afastar a responsabilidade civil por abandono afetivo, já que a criança tem necessidades que não podem ser adquiridas monetariamente.

\section{Luiz Felipe Brasil afirma:}

O papel dos pais não se limita ao dever de sustento, de prover materialmente o filho com os meios necessários à subsistência orgânica. Vai muito além, para abranger a subsistência emocional, e a função psicopedagógica, de educação e assistência em geral. Na medida em que não é cumprido esse irrenunciável papel, por injustificável ausência paterna, exsurge o dano que há de ser reparado. ${ }^{60}$

A reparação civil do dano moral não estabelece um valor para a dor ou coloca à venda um bem moral. Utiliza-se da capacidade que o dinheiro tem de proporcionar satisfações materiais e espirituais que podem atenuar em parte as consequências do dano e não deixar o causador da lesão impune. ${ }^{61}$ Sendo assim, a indenização por abandono afetivo não tem como objetivo compelir o pai a amar ou estabelecer um preço aos sentimentos que foram negados. ${ }^{62}$ Unicamente o dinheiro em espécie não pode

${ }^{59}$ BRASIL. Superior Tribunal de Justiça. Recurso Especial n. 1.159.242 - SP (2009/0193701-9). Recorrente: Antônio Carlos Jamas dos Santos. Recorrido: Luciane Nunes de Oliveira Souza. Relatora: Min. Nancy Andrighi. Brasília, 24 de abril de 2012. Revista Eletrônica da Jurisprudência do STJ, 10 maio 2012. passim. Disponível em: <https://ww2.stj.jus.br/websecstj/cgi/revista/REJ.cgi/ITA? seq $=1067604 \&$ tipo $=0 \&$ nreg $=200901937019 \&$ SeqCgrmaS essao $=\&$ CodOrgaoJgdr $=\& d t=20120510 \&$ formato $=P D F \& s$ alvar $=$ false $>$.

${ }^{60}$ SANTOS, Luiz Felipe Brasil. Pais, filhos e danos. Disponível em: <http://www.ibdfam.org.br/artigos/ 141/Pais\%2C+filhos+e+danos>. Acesso em: 22 ago. 2018.

${ }^{61}$ CAHALI, Yussef Said. Dano moral. São Paulo: RT, 2005. p. 28.

${ }^{62}$ SANTOS, loc. cit. 
suprir a ausência paterna ou apagar a dor e o abalo psíquico do filho negligenciado.

O objetivo da responsabilidade civil é então proporcionar recursos para que o filho possa utilizar de tratamentos psicológicos a fim de amenizar todo o sofrimento e os traumas causados pela ausência do genitor.

Rodrigo da Cunha Pereira acrescenta que a indenização tem apenas um valor simbólico e serve como punição ao genitor que não cumpriu com os encargos da criação de um filho. ${ }^{63}$

Tal entendimento está de acordo com a função punitiva da indenização por dano moral que se revela por meio da fixação da indenização em um valor significativo para o causador do dano, demonstrando-lhe que a conduta lesiva praticada é inadmissível e não deve se repetir.

O caráter socioeducativo e pedagógico da responsabilização civil por abandono afetivo se manifesta ao romper com o paradigma da impunidade que paira sobre os atos ilícitos na relação paterno-filial e no consequente desestímulo à prática dessa conduta já não mais aceita pela sociedade. ${ }^{64}$

Os filhos, devido à falta de afeto, desenvolvem um sentimento de rejeição e inferioridade em relação aos outros que puderam conviver com ambos os pais. Esses sentimentos refletirão em relações instáveis no futuro. Nesse sentido, a indenização poderia proporcionar acesso à orientação psicológica para o tratamento das consequências advindas da ausência de convivência com o genitor. ${ }^{65}$

\footnotetext{
${ }^{63}$ PEREIRA, Rodrigo da Cunha. Nem só de pão vive o Homem: responsabilidade civil por abandono afetivo. Disponível em: <http://www.mpce.mp.br/orgaos/CAO CÓDIGOCILVIL/dirFamila/artigos/05_nem.so.de.pao.viv e.o.homem.pdf>. Acesso em: 10 ago. 2018.

64 DIAS, Maria Berenice. Manual de direito das famílias. 6. ed. São Paulo: Revista dos Tribunais, 2010. p. 455.

65 CARDIN, Valéria Silva Galdino. Dano Moral no Direito de Família. São Paulo: Saraiva, 2012. p. 239.
}

Além disso, como já exposto anteriormente em muitos casos os filhos são tratados de maneira depreciativa em relação aos irmãos que convivem com o genitor, causando danos a sua imagem. ${ }^{66}$

Não são todos os casos de ausência parental que devem ser indenizados, mas apenas aqueles em que realmente ficou comprovado que o descaso acarretou situações vexatórias e humilhantes à imagem e à personalidade do filho. ${ }^{67}$

Há de se considerar, entretanto, a existência de diversos casos de ausência paterna oriunda da ignorância do estado parental pelo genitor, que são hipóteses em que a mãe não comunica ao pai a gestação, e, nesse contexto, não há o que cogitar em responsabilização civil do pai pela falta de assistência. ${ }^{68}$

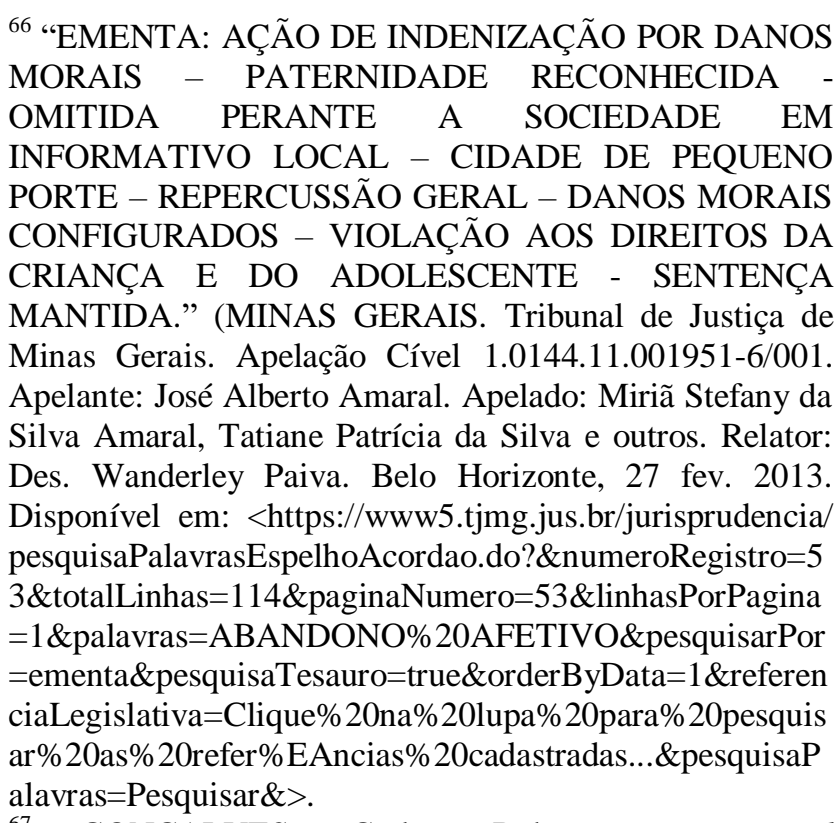
67 GONÇALVES, Carlos Roberto. Direito civil brasileiro: Responsabilidade Civil. 7. ed. São Paulo: Saraiva, 2012. v. 4. p. 361.

${ }^{68}$ HIRONAKA, Giselda. Pressuposto, elementos e limites do dever de indenizar por abandono afetivo. Publicado em 22 abr. 2007. Disponível em: <http://www.ibdfam. org.br/artigos/288/Pressuposto $\% 2 \mathrm{C}+$ elementos+e+limites+ do+dever+de+indenizar+por+abandono+afetivo>. Acesso em: 13 ago. 2018. 


\section{CONCLUSÃO}

A repersonalização das relações familiares deu proteção constitucional a todas as organizações familiares. $\mathrm{O}$ vínculo matrimonial e biológico abriu caminho para que o vínculo afetivo passasse a ser o elemento preponderante na constituição de uma família. As relações familiares passaram então a pautar-se na igualdade, na solidariedade, nos vínculos afetivos e na dignidade de cada um de seus membros. Além disso, crianças e adolescentes conquistaram inúmeros direitos e garantias que contribuem para o sadio desenvolvimento de sua personalidade e identidade.

Nesse contexto, tanto o poder familiar como o direito de visita se configuram como um conjunto de deveres dos pais em benefício do filho que deve ser exercido em igualdade de condições por ambos os genitores. Em um Estado Democrático de Direito que zela pela igualdade de direitos e deveres entre homem e mulher, um dos pais não pode ser sobrecarregado com todos os encargos da criação de um filho enquanto o outro se mantém indiferente a essas atribuições.

$\mathrm{O}$ abandono afetivo configura-se como o descumprimento das atribuições do poder familiar, sendo fruto de uma parentalidade não responsável, ferindo os direitos e as garantias fundamentais dos infantes, causando assim danos permanentes à sua personalidade. $\mathrm{O}$ exercício do poder familiar deve obedecer aos princípios da dignidade da pessoa humana e da parentalidade responsável, devendo ser exercido de forma a garantir o melhor interesse da criança em todos os seus aspectos.

É direito de toda criança ou adolescente conviver com ambos os pais e receber toda a assistência material, moral, intelectual necessária ao seu pleno desenvolvimento. Quando o pai ou a mãe se nega intencionalmente de dispender os cuidados necessários em relação ao filho, acaba por praticar ato ilícito causador de dano moral, dando ensejo à sua responsabilização em decorrência de sua conduta negligente.

A destituição do poder familiar, medida anteriormente adotada nesses casos, tem se mostrado ineficiente por representar uma verdadeira premiação, ao libertá-lo definitivamente das obrigações que não deixa cumprir.

A indenização por abandono afetivo não tem como objetivo compelir o pai a amar ou (re)estabelecer laços afetivos, tampouco tarifar os sentimentos que foram negados. Condena-se o descumprimento dos deveres paternos ou maternos, que são fundamentais ao desenvolvimento da personalidade dos filhos.

Conclui-se, portanto, que o fim da indenização é proporcionar um meio para que o filho possa atenuar as consequências psicológicas acarretadas pela ausência do referencial paterno e que tem caráter dissuasório, rompendo com o paradigma da impunidade e desestimulando a prática de atos ilícitos dessa natureza.

\section{REFERÊNCIAS}

BOSCHI, Fabio Bauab. Direito de visita. São Paulo: Saraiva, 2005.

BRASIL. Superior Tribunal de Justiça. Recurso Especial n. 1.159.242 - SP (2009/0193701-9). Recorrente: Antônio Carlos Jamas dos Santos. Recorrido: Luciane Nunes de Oliveira Souza. Relatora: Min. Nancy Andrighi. Brasília, 24 de abril de 2012. Revista Eletrônica da Jurisprudência do STJ, 10 maio 2012. Disponível em: <https://ww2.stj.jus.br/websecstj/cgi/revista/REJ.cgi/ ITA $?$ seq $=1067604 \&$ tipo $=0 \&$ nreg $=200901937019 \&$ SeqCgrmaSessao $=\&$ CodOrgaoJgdr $=\& d t=201205$ $10 \&$ formato $=$ PDF \&salvar $=$ false $>$. 
BRASIL. Superior Tribunal de Justiça. Recurso Especial n. 757.411 - MG (2005/0085464-3). Recorrente: V.P.F.O. Recorrido: A. B. F. (menor), assist. por V. B. F. Relator: Min. Fernando Gonçalves. Brasília, 29 nov. 2005. DJU, 27 mar. 2006.

CAHALI, Yussef Said. Dano moral. São Paulo: RT, 2005.

CARDIN, Valéria Silva Galdino. Dano Moral no Direito de Família. São Paulo: Saraiva, 2012.

CARDIN, Valéria Silva Galdino; FROSI, Vitor Eduardo. O afeto como valor jurídico. In: ENCONTRO NACIONAL DO CONPEDI, 19., 9-12 jul. 2010, Fortaleza. Anais... Florianópolis: Fundação Boiteux, 2010. p. 6857-6869.

CAVALIERI FILHO, Sergio. Programa de responsabilidade civil. 8. ed. São Paulo: Atlas, 2009.

COELHO, Fábio Ulhôa. Curso de direito civil: Família - Sucessões. 5. ed. São Paulo: Saraiva, 2012, v. 5.

CONRADO, Marcelo; PINHEIRO, Rosalice Fidalgo (Coord.). Direito Privado e Constituição: ensaios para uma recomposição valorativa da pessoa e do patrimônio. Curitiba: Juruá, 2009.

COULANGES, Fustel de. A cidade antiga. Trad. José Cretella Júnior. 7. ed. São Paulo: Revista dos Tribunais, 2011.

DIAS, Maria Berenice. Manual de direito das famílias. 6. ed. São Paulo: Revista dos Tribunais, 2010.

DIAS, Maria Berenice; PEREIRA, Rodrigo da Cunha (Org.). Direito de Família e o Novo Código Civil. 3. ed. Belo Horizonte: Del Rey, 2003.

DINIZ, Maria Helena. Curso de Direito Civil Brasileiro: Direito de Família. 27. ed. São Paulo: Saraiva, 2012, v. 5.

DINIZ, Maria Helena. Curso de Direito Civil Brasileiro: Responsabilidade Civil. 26. ed. São Paulo: Saraiva, 2012. v. 7.

GAGLIANO, Pablo Stolze; PAMPLONA FILHO, Rodolfo. Novo Curso de Direito Civil: Direito de Família. 2. ed. São Paulo: Saraiva, 2012, v. 6.

GAMA, Guilherme Calmon Nogueira da. A parentalidade responsável e o cuidado: novas perspectivas. Revista do Advogado, São Paulo, v. 101, p. 29-36, dez. 2008.

GONÇALVES, Carlos Roberto. Direito civil brasileiro: Direito de Família. 9. ed. São Paulo: Saraiva, 2012, v. 6.

GONÇALVES, Carlos Roberto. Direito civil brasileiro: Responsabilidade Civil. 7. ed. São Paulo: Saraiva, 2012, v. 4.

HIRONAKA, Giselda. Direito ao pai. Revista Igualdade, v. 8, n. 26, p. 34-36, 2000. Disponível em: <http://www2.mp.pr.gov.br/cpca/telas/ca_igualdade_22_2_2.php> Acesso em: 18 ago. 2018. 
HIRONAKA, Giselda. Os contornos jurídicos da responsabilidade afetiva na relação entre pais e filhos - além da obrigação legal de caráter material. Disponível em: <www.flaviotartuce.adv.br/artigosc/Giselda_resp2.doc>. Acesso: 15 ago. 2018.

HIRONAKA, Giselda. Pressuposto, elementos e limites do dever de indenizar por abandono afetivo. Publicado em 22 abr. 2007. Disponível em: $<$ http://www.ibdfam.org.br/artigos/288/Pressuposto\%2C+elementos+e+limites+do+dever+de+indeni zar+por+abandono+afetivo>. Acesso em: 13 ago. 2018.

LÔBO, Paulo. Direito civil: famílias. 4. ed. São Paulo: Saraiva, 2011.

MACIEL, Kátia (Coord.). Curso de Direito da Criança e do Adolescente: aspectos teóricos e práticos. Rio de Janeiro: Lumen Juris, 2010.

MADALENO, Rolf. Curso de Direito de Família. 4. ed. Porto Alegre: Forense, 2011.

MADALENO, Rolf. O custo do abandono afetivo. Disponível em: <http://www.rolfmadaleno. com.br/novosite/conteudo.php?id=943> Acesso em: 16 ago. 2018.

MADALENO, Rolf. O dano moral na investigação de paternidade. Disponível em: <http://www.rolfmadaleno.com.br/novosite/conteudo.php?id=32\#_ftnref11>. Acesso em: 19 ago. 2018.

MARMELSTEIN, George. Curso de Direitos Fundamentais. São Paulo, Atlas. 2008

MICELI, Mariana Sant'Ana. Por uma visão crítica do Direito da Criança e do Adolescente. Revista Estudos Jurídicos UNESP, Franca, ano 14, n. 2, p. 275-288, 2010. Disponível em: <http://periodicos.franca.unesp.br/index.php/estudosjuridicosunesp/article/view/255>. Acesso em: 12 ago. 2018.

MINAS GERAIS. Tribunal de Justiça de Minas Gerais. Apelação Cível 1.0144.11.001951-6/001. Apelante: José Alberto Amaral. Apelado: Miriã Stefany da Silva Amaral, Tatiane Patrícia da Silva e outros. Relator: Des. Wanderley Paiva. Belo Horizonte, 27 fev. 2013. Disponível em: <https://www5.tjmg.jus.br/jurisprudencia/pesquisaPalavrasEspelhoAcordao.do?\&numeroRegistro=5 $3 \&$ totalLinhas $=114 \&$ paginaNumero $=53 \&$ linhasPorPagina $=1 \&$ palavras $=$ ABANDONO $\% 20$ AFETIV O\&pesquisarPor $=$ ementa\&pesquisaTesauro $=$ true\&orderByData $=1 \&$ referenciaLegislativa $=$ Clique $\% 2$ 0na\%20lupa \%20para\%20pesquisar\%20as\%20refer\%EAncias\%20cadastradas...\&pesquisaPalavras=P esquisar\&>.

PEREIRA, Rodrigo da Cunha (Coord.). Família e responsabilidade: teoria e prática do Direito de Família. Porto Alegre: Magister/IBDFAM, 2010.

PEREIRA, Rodrigo da Cunha. Nem só de pão vive o Homem: responsabilidade civil por abandono afetivo. Disponível em: <http://www.mpce.mp.br/orgaos/CAOCÓDIGOCILVIL/ dirFamila/artigos/05_nem.so.de.pao.vive.o.homem.pdf>. Acesso em: 10 ago. 2018.

PEREIRA, Rodrigo da Cunha. Princípios fundamentais e norteadores para a organização jurídica da família. 2005. 157 f. Tese (Doutorado em Direito) - Universidade Federal do Paraná, Curitiba, 
2004. Disponível em: <http://dspace.c3sl.ufpr.br/dspace/bitstream/handle/1884 /2272/tese_dr. rodrigo da cunha.pdf?sequence=1>. Acesso em: 10 ago. 2018.

PEREIRA, Tânia da Silva. Cuidado no Direito de Família, Infância e Juventude. Disponível em: < http://www.cartaforense.com.br/conteudo/entrevistas/cuidado-no-direito-de-familia-infancia-ejuventude/10588>. Acesso em: 6 ago. 2018.

RODRIGUES, Silvio. Direito civil. 26. ed. São Paulo: Saraiva, 2001.

SANTOS, Luiz Felipe Brasil. Pais, filhos e danos. Disponível em: <http://www.ibdfam.org.br/artigos/141/Pais\%2C+filhos+e+danos>. Acesso em: 22 ago. 2018.

SCHREIBER, Anderson. Novos paradigmas da responsabilidade civil. 2. ed. São Paulo: Atlas, 2009.

Recebido em: 29/09/2017

Aceito em: 14/12/2018 
